\title{
Le virus VIH-1 et la mort neuronale: étude des effets de la protéine de l'enveloppe virale gp120
}

L'infection du système nerveux par le virus de l'immunodéficience humaine de type 1 (VIH-1) peut se manifester par une encéphalopathie et une mort neuronale [1]. La physiopathogénie des manifestations neurologiques liées à ce rétrovirus est cependant imparfaitement comprise. Deux mécanismes pourraient rendre compte des lésions neuronales observées au cours des encéphalopathies liées au virus VIH-1, une neurotoxicité directe de l'un des constituants du virus (par exemple, la protéine gp120) ou une neurotoxicité indirecte, faisant intervenir une neurotoxine libérée par les cellules infectées par le virus VIH-1 (par exemple, des macrophages). Ainsi, le groupe de Lipton a proposé que la libération de glutamate par les macrophages pourrait exercer un effet excitotoxique sur les neurones via l'activation du récepteur NMDA. Cela expliquerait pourquoi la toxicité de la gp120 est prévenue par les antagonistes de ces récepteurs [2, 3]; ces données ont cependant été contredites. Les résultats des études des effets de la protéine de l'enveloppe virale gp120 in vivo sont également très contradictoires. Certains auteurs observent une mort neuronale dans le système nerveux de rat [4], alors que d'autres auteurs n'observent aucun effet dans le système nerveux de rats adultes après injection intra-cérébro-ventriculaire de la gp120 [5].

Nous avons utilisé deux types de préparations in vitro afin d'étudier la neurotoxicité de la gp120 et de tester, en particulier, l'hypothèse selon laquelle la mort neuronale induite par cette protéine serait de type apoptotique (agrégation de la chromatine, formation de corps apoptotiques, etc.) : des cultures primaires de neurones hippocampiques, d'une part, et, d'autre part, des cultures organotypiques de tranches d'hippocampe qui préservent l'organisation cytoarchitectonique observée in vivo et permettent d'éviter les problèmes liés à la diffusion ou au métabolisme de la protéine ou aux altérations de perméabilité de la barrière hémato-encéphalique observées lors de l'injection de la protéine in vivo. Ce modèle permet donc de tester les mécanismes d'action cellulaires et moléculaires de la gp120 proches des conditions in vivo $[6,7]$. La gp120 induit effectivement une dégénérescence massive des neurones hippocampiques en culture primaire, et cette mort est morphologiquement de type apoptotique car l'on observe une coloration TUNEL positive des neurones (marquage des fragments d'ADN par l'enzyme désoxynucleotidyl terminal transférase). Des études en microscopie électronique sont en cours afin d'analyser les caractéristiques morphologiques de cette mort neuronale. Sur des cultures organotypiques également la mort neuronale induite par la gp120 présente des similitudes avec l'apoptose neuronale induite dans l'hippocampe et le cortex par l'ischémie cérébrale ou par les convulsions épileptiques. L'étude en microscopie confocale des effets de la gp120 montre que la protéine augmente le calcium intracellulaire neu- ronal de façon persistante, y compris en présence d'antagonistes du récepteur NMDA et avec une cinétique différente de celle induite par le NMDA. Le mécanisme d'action de la gp120 n'implique donc pas l'activation de ces récepteurs.

\section{D.A. \\ I.M. \\ S.G. \\ Y.B.A. \\ A.R.}

1. Adle-Biassette H, Levi Y, Colombel M, Poron F, Natchev S, Keohane C, Gray F. Neuronal apoptosis in HIV infection in adults. Neuropathol Appl Neurobiol 1995; 21 : 218-27.

2. Lipton SA, Sucher NJ, Kaiser PK, Dreyer EB. Synergistic effect of HIV coat protein and NMDA receptor-mediated neurotoxicity. Neuron 1991; 7 : 111-8.

3. Lannuzel A, Liedo P, Ould Lamgitnia H, Vincent J, Tardieu M. HIV-1 envelope proteins gp120 and gp160 potentiate NMDA-induced $\mathrm{Ca}^{2+}$, increase, alter $\mathrm{Ca}^{2+}$ homeostasis and induce neurotoxicity in human embryonic neurons. Eur J Neurosci 1995; 7: 2285-93

4. Hill JM, Mervis RF, Avidor R, Moody TW, Brennemen DE. HIV envelope protein-induced neuronal damage and retardation of behavioral development in rat neonates. Brain Res 1993; 603: 222-33. 5. Bagetta G, Tiziana Corasaniti M, Aloe L, Berliocchi L, Costa N, Finazzi-Agro A, Nistico G. Intracerebral injection of human immunodeficiency virus type 1 coat protein gp120 differentially affects the expression of nerve growth factor and nitric oxide synthase in the hippocampus of rat. Proc Natl Acad Sci USA 1996; 93: 928-33.

6. Aggoun-Zouaoui D, Charriaut-Marlangue C, Rivera S, Jorquera I, Ben-Ari Y, Represa A. The HIV-1 envelop protein gp120 induces neuronal apoptosis in hippocampal slices. NeuroReport 1996; 7: 433-6. 7. Charriaut-Marlangue C, Aggoun-Zouaoui D, Represa A, Ben-Ari Y. Apoptotic features of selective neuronal death in ischemia, epilepsy and HIV-1 gp120 protein toxicity. Trends Neurosci 1996; 19: $109-14$.

Figure 1. Effets apoptotiques de la protéine gp120 sur les neurones hippocampiques. A : Vue globale d'une tranche organotypique d'hippocampe colorée au violet de crésyl. Les tranches sont mises en culture pendant 3 semaines, sont traitées avec 200 pM de gp120 pendant 24 heures, puis fixées avec du paraformaldehyde 4\% et coupées au cryostat $(15 \mu \mathrm{m})$. G X 40. B : Neurone dégénéré après traitement à la gp120, coloré au bleu de toluidine (grande flèche) sur une coupe semi-fine d'hippocampe de $1 \mu \mathrm{m}$. G=x 1000. C : Neurone presentant un marquage TUNEL positif au niveau du noyau sur une coupe semi-fine d'hippocampe (marquage par la désoxynucléotidyl terminal-transférase, indicateur de procesus apoptotiques). $G=x 1000$. D: Neurone observé au microscope électronique présentant un cytoplasme très dense ainsi qu'un début de condensation de la chromatine à la périphérie du noyau (flèches), indicatives d'un commencement de phénomène apoptotique. $G=x 4300$. E: Neurone primaire d'hippocampe présentant un double marquage, Tunel au niveau nucléaire (marqueur d'apoptose) et par MAP5, un anticorps sélectif des neurones. G=x 1000. F : Augmentation du calcium intracellulaire dans deux neurones d'une tranche d'hippocampe de rat âgé de 10 jours induit après application de 200pM de gp120. Le taux de calcium a été mesuré au microscope confocal à l'aide du Fluo-3-AM. 

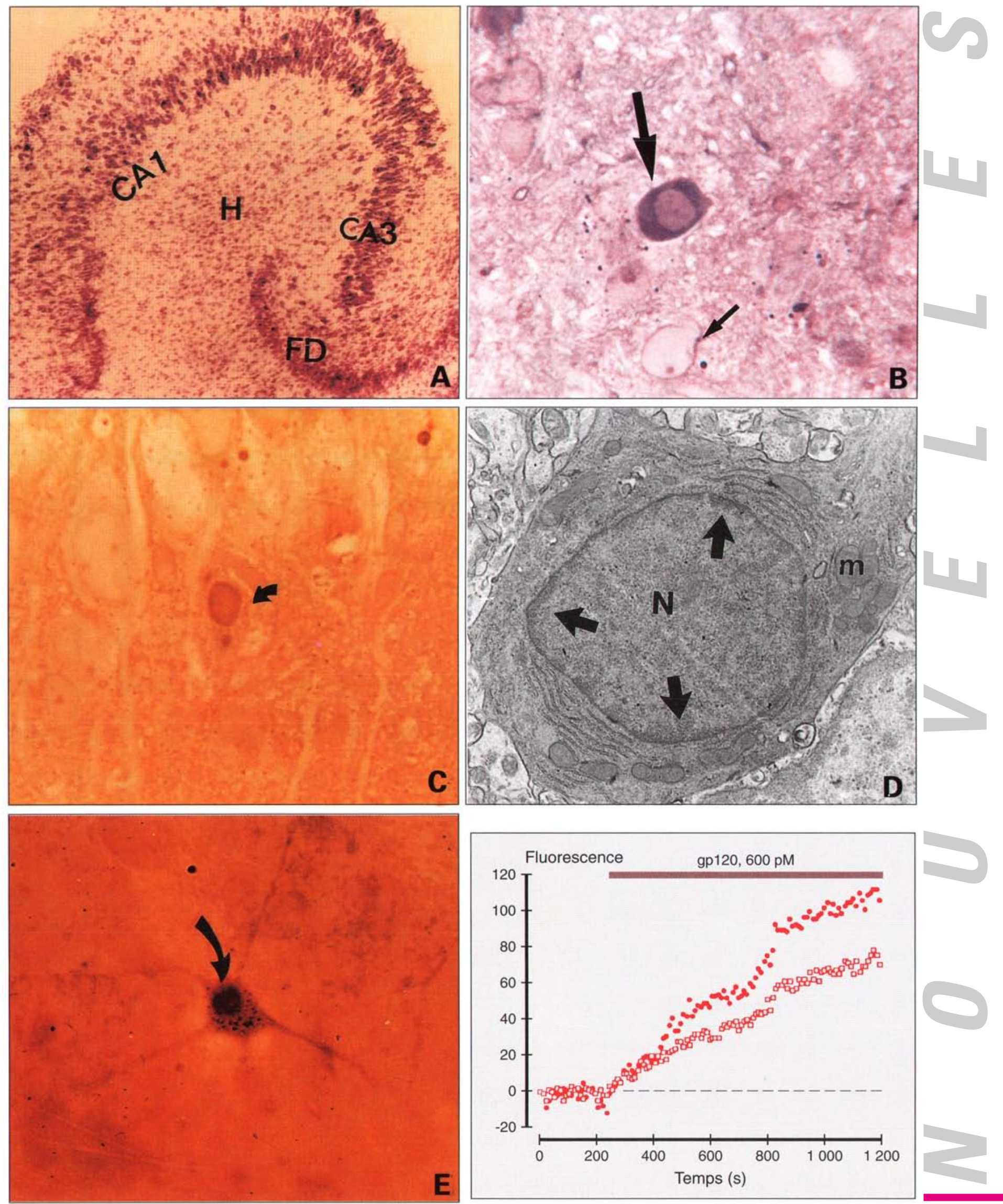